\title{
Somatic Mutation Analysis
}

National Cancer Institute

\section{Source}

National Cancer Institute. Somatic Mutation Analysis. NCI Thesaurus. Code C157371.

A procedure used to detect and identify mutations in the genome of a somatic cell sample. 